\title{
Reflective materials enhance 'Fuji' apple color
}

\author{
Harry Andris $\square$ Carlos H. Crisosto
}

\begin{abstract}
Red color development is an important factor for consumer acceptance of California 'Fuji' apples. Several attempts to improve red color development, including delaying harvest, have been unsuccessful in warm production areas. In California, late harvest has been associated with physiological problems such as skin cracking and internal browning. A study conducted under the warm San Joaquin Valley conditions reveals a new approach to economically enhance 'Fuji' red color. The use of reflective materials between tree rows enhanced red color development without reducing fruit quality under poor and good orchard conditions.
\end{abstract}

Although red color does not affect flavor, it is an important factor for consumer acceptance of apples. Cyanidin is the immediate precursor to idaein, the pigment responsible for the red color on 'Fuji' apples. It is well known that the red pigmentation formation process depends mainly on environmental factors such as temperature, light quality and light interception. Cultural practices such as pruning, thinning, fertilization (nitrogen and potassium) and plant growth regulators influence red color formation. Other factors such as smoke, dust, clouds and rain may indirectly affect red color formation by reducing light exposure.

In general, apples form red color best in climates with clear bright days and cool nights during the preharvest period. Night temperatures below $68^{\circ} \mathrm{F}\left(18^{\circ} \mathrm{C}\right)$ enhance red color formation in 'Fuji' apples, but daily warm

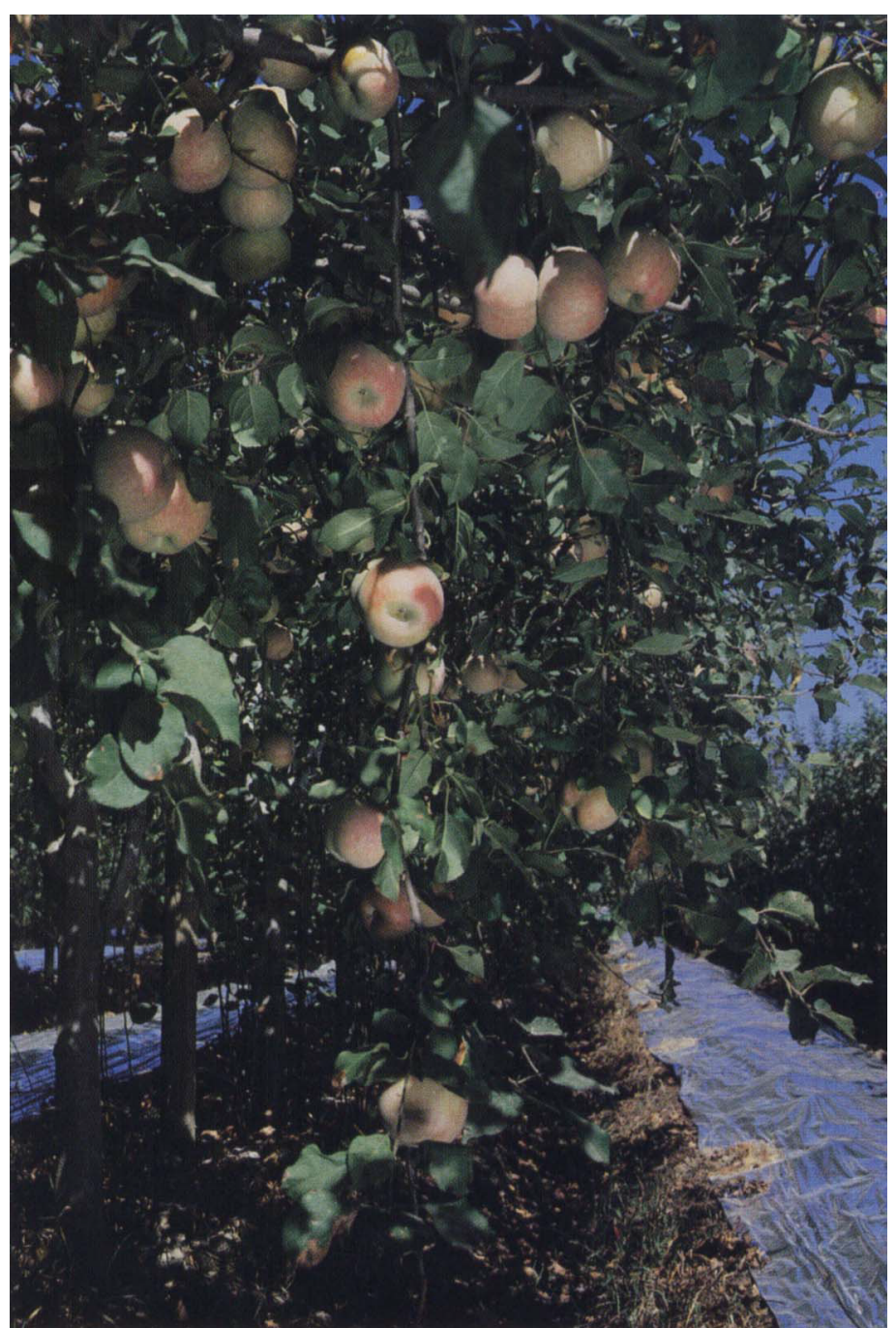

temperatures can negate the positive effect of the cold night temperatures. Viveros and Bentley demonstrated that San Joaquin Valley 'Fuji' apples grown on the outside of the canopy were larger and had more red surface area, as well as greater red color intensity, than did apples grown inside the canopy. Excess nitrogen and improper pruning can reduce color development by preventing proper light distribution.

Ethephon, an ethylene-releasing product that is applied as a preharvest application, has been used commercially with success to promote red color development in early- and midseason red cultivars in other countries. However, applications of ethephon on 'Fuji' in the warm conditions of the central San Joaquin Valley did not improve red color formation (Day, Kevin). It appears that ethephon is not capable of inducing red color forma- tion when light and temperature requirements for red color formation are not met.

High-quality water applications have been suggested to reduce fruit temperature (evaporative cooling) and thereby enhance color formation under warm climate conditions. Use of this technique should be studied in detail prior to commercial application because of the potential negative side effects.

Although reflective materials have been used on apples in Japan and China to enhance color development, the approach is new in the United States. This article summarizes 2 years' work on 'Fuji' apple skin-color development under the warm San Joaquin Valley conditions.

\section{Aluminum foil and plastic}

We evaluated reflective materials for red color development during the 
1993 and 1994 seasons on 'Fuji' apples growing in the San Joaquin Valley. In the 1993 trial, an aluminum foil laminated to a cloth backing (Namura Co., Japan) and a polyethylene plastic (Specialty Ag., Reedley) were laid on the soil surface between tree rows in a 'Fuji' apple orchard trained to a Lincoln trellis. We tested reflective material in widths of 20 and 40 inches.
Based on the results of the 1993 trial, we modified treatments for 1994 . We expanded the cloth-backed aluminum foil to 48 inches wide, and replaced the 40 -inch polyethylene material with 60 -inch polypropylene plastic (Specialty Ag.) in 1994. One month before the predicted harvest date (180 to 190 days after full bloom), the reflective materials were placed in the or-

\begin{tabular}{|c|c|c|c|}
\hline \multirow[b]{2}{*}{ Treatment } & \multirow{2}{*}{$\begin{array}{l}\text { Fruit surface } \\
\text { with red color }\end{array}$} & \multicolumn{2}{|c|}{ Color intensityt } \\
\hline & & $\mathrm{Hue}^{\circ}$ & $a^{*}$ \\
\hline & $\%$ & & \\
\hline Control (bare soil) & 14.4 & 185.64 & 12.83 \\
\hline $20 "$ reflective plastic & 23.5 & 171.36 & 12.29 \\
\hline $20 "$ reflective foil & 25.9 & 165.67 & 12.01 \\
\hline $40 "$ reflective plastic & 31.6 & 170.87 & 11.63 \\
\hline $40 "$ reflective foil & 36.0 & 159.08 & 10.98 \\
\hline P-value & 0.005 & 0.10 & 0.03 \\
\hline LSD 0.05 & 9.6 & ND $\ddagger$ & 1.1 \\
\hline
\end{tabular}

† Smaller red hue ${ }^{\circ}$ and $\mathrm{a}^{*}$ value represent a brighter red color.

$\ddagger N D=$ No significant difference.

TABLE 2. 'Fuji' apple color characteristics affected by using reflective materials (Lincoln trellis), north-south rows, 1994

\begin{tabular}{|c|c|c|c|c|c|c|c|c|}
\hline \multirow[b]{2}{*}{ Treatment } & \multirow[b]{2}{*}{ Firmness } & \multirow[b]{2}{*}{ ssc } & \multirow[b]{2}{*}{ Starch } & \multirow{2}{*}{$\begin{array}{l}\text { Titratable } \\
\text { acidity }\end{array}$} & \multirow[b]{2}{*}{$\mathrm{pH}$} & \multirow{2}{*}{$\begin{array}{l}\text { Fruit surface } \\
\text { with red color }\end{array}$} & \multicolumn{2}{|c|}{ Color intensity* } \\
\hline & & & & & & & Red hue $^{\circ}$ & Green hue $^{\circ}$ \\
\hline & & & & & & $\%$ & & \\
\hline Control (bare soil) & 12.6 & 13.7 & 5.28 & 0.28 & 3.9 & 7.4 & 102.30 & 111.29 \\
\hline $60 "$ reflective plastic & 12.9 & 13.3 & 5.4 & 0.28 & 3.9 & 14.3 & 98.39 & 110.33 \\
\hline $48^{\prime \prime}$ reflective foil & 12.2 & 13.7 & 5.2 & 0.27 & 3.9 & 19.3 & 93.91 & 109.83 \\
\hline P-value & 0.226 & 0.222 & 0.228 & 0.957 & 0.518 & 0.0001 & 0.0001 & 0.008 \\
\hline LSD 0.05 & NDt & ND & ND & ND & ND & 3.6 & 3.3 & 0.91 \\
\hline
\end{tabular}

*Smaller hue values represent brighter red color (red hue ${ }^{\circ}$ ) and more yellow background color (green hue ${ }^{\circ}$ ). †ND $=$ No significant difference.

TABLE 3. 'Fuji' apple color characteristics affected by using reflective materials (central leader), north-south rows, 1994

\begin{tabular}{|c|c|c|c|c|c|c|c|c|}
\hline \multirow[b]{2}{*}{ Treatment } & \multirow[b]{2}{*}{ Firmness } & \multirow[b]{2}{*}{ SSC $^{\star}$} & \multirow{2}{*}{ Starch } & \multirow{2}{*}{$\begin{array}{c}\text { Titratable } \\
\text { acidity }\end{array}$} & \multirow[b]{2}{*}{$\mathrm{pH}$} & \multirow{2}{*}{$\begin{array}{l}\text { Fruit surface } \\
\text { with red color }\end{array}$} & \multicolumn{2}{|c|}{ Color intensityt } \\
\hline & & & & & & & Red hue ${ }^{\circ}$ & Green hue \\
\hline & & & & & & $\%$ & & \\
\hline Control (bare soil) & 12.8 & 14.3 & 4.7 & 0.26 & 3.9 & 23.4 & 87.26 & 109.24 \\
\hline $60 "$ reflective Plastic & 12.9 & 14.3 & 5.0 & 0.26 & 3.9 & 30.0 & 85.70 & 108.39 \\
\hline 48 " reflective Foil & 12.7 & 14.7 & 4.9 & 0.27 & 3.9 & 36.1 & 82.31 & 107.92 \\
\hline$P$-value & 0.887 & 0.1128 & 80.5232 & 20.1402 & 0.9619 & 0.0042 & 0.03 & 0.04 \\
\hline LSD 0.05 & $\mathrm{ND} \ddagger$ & ND & ND & ND & ND & 7.2 & 3.73 & 1.02 \\
\hline
\end{tabular}

"Soluble solids concentration $\mp N D=$ No significant difference.

TABLE 4. Impact of reflective materials on the number of boxes commercially packed by grade, 'Fuji' apple north-south Lincoln trellis, 1994

\begin{tabular}{|c|c|c|c|}
\hline \multirow[b]{2}{*}{ Treatments } & \multicolumn{3}{|c|}{ Percentage of fruit grade distribution boxes } \\
\hline & Fancy & US \#1 & Utility \\
\hline & \multicolumn{3}{|c|}{ 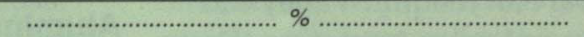 } \\
\hline Control (bare soil) & 30.4 & 26.6 & 42.9 \\
\hline $60 "$ reflective plastic & 33.3 & 33.3 & 33.3 \\
\hline 48 " reflective foil & 35.9 & 38.9 & 25.1 \\
\hline
\end{tabular}

chards. Reflective materials were randomly placed on the ground between the north/south-oriented tree rows in a 12-year-old standard 'Fuji' orchard grafted on EM-26 rootstock trained to a central leader (12-feet-by-14-feet spacing) and a 9-year-old standard 'Fuji' orchard grafted on EM-26 rootstock trained on a Lincoln trellis (8-feet-by-14-feet spacing).

The orchards were located 1 mile apart on sandy loam (Hanford series) near Parlier. Both orchards were furrowirrigated with well water; rows were oriented north/south. We used a randomized complete block design. The 1994 trial consisted of 24 replications of 72 trees per block with 24 trees per plot $(8$ trees per row and 3 rows per plot), with 4 guard trees between treatments down each row. Each treatment was randomized within the block and consisted of 3 rows of 8 trees (plot), each with reflective materials laid on the soil on both sides of the row.

\section{Fruit color and quality}

During the 1994 season, trees growing under the 60-inch-wide plastic and the 48-inch-wide foil treatments had 3 and 5 times more light, respectively, inside the canopy than control trees. Fruit size and grade distribution were determined for fruit from the orchard on a Lincoln trellis during commercial packing operations on each harvest date. On the first (Sept. 26, 1994) and second (Oct. 14, 1994) harvest dates, we combined fruit from replications within treatment so we would have a quantity large enough to process in a commercial packinghouse.

Fruit quality evaluation included percent of the apple surface with red color, red and green skin color intensity parameters, flesh firmness, starch, $\mathrm{pH}$, acidity and soluble solids concentration, measured on 30 randomly selected fruit per replicate. We measured the percent of fruit surface covered by red color. Red color was described by using the Minolta Chromameter CR200, which measured two color parameters ( $a^{*}$ and $b^{*}$ values). Hue angle $\left(\arctan b^{*} / a^{*}\right)$, a color-intensity indicator for determining color differences in fruit that ripen from green to either yellow or shades of red, was calcu- 

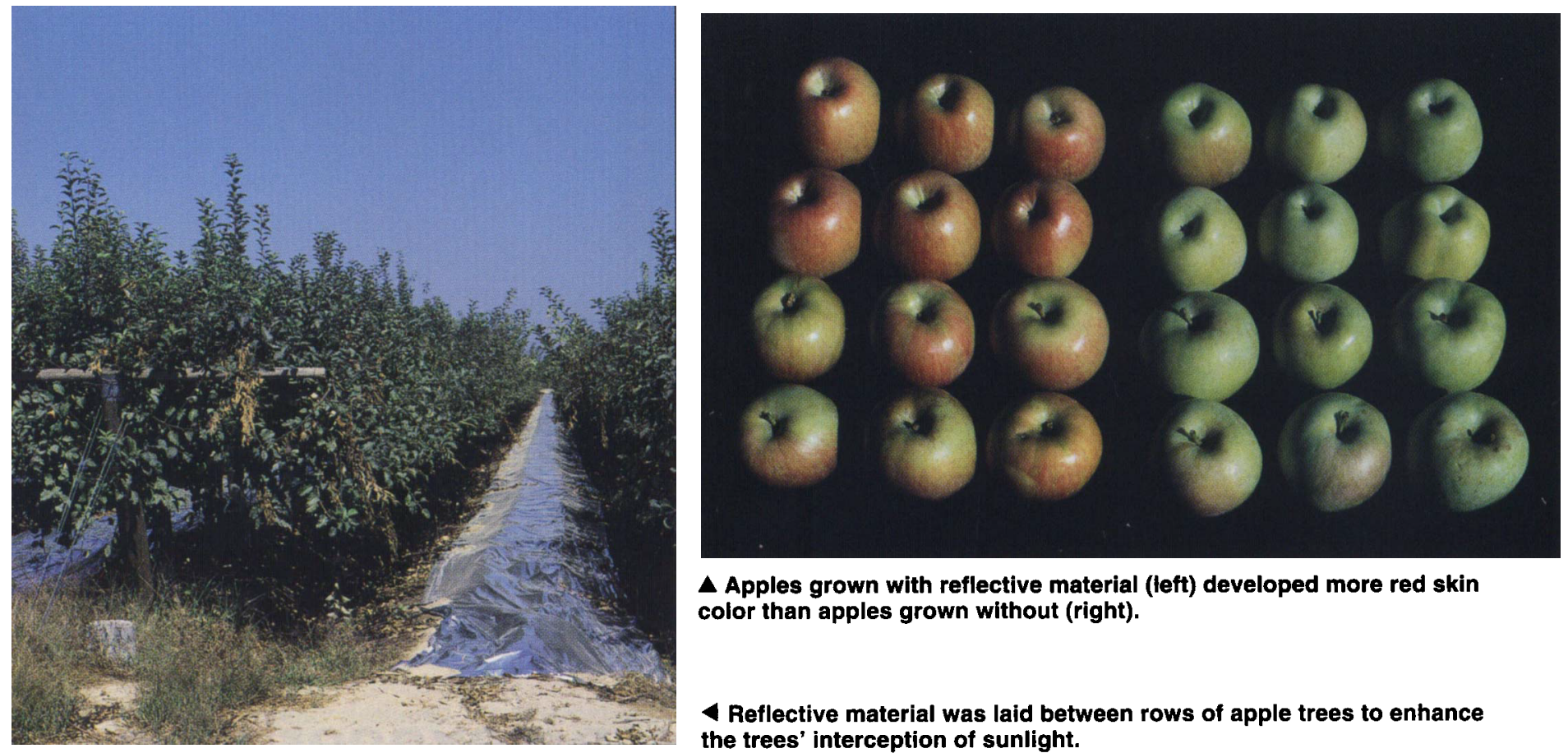

$\Delta$ Apples grown with reflective material (teft) developed more red skin color than apples grown without (right).

\section{Reflective material was laid between rows of apple trees to enhance the trees' interception of sunlight.}

lated from positive $a^{*}$ (red color intensity) and positive $b^{*}$ values (yellow color intensity). Color values were measured twice at the reddest (red hue) and greenest (green hue) point of the fruit's equator (side). Fruit firmness was measured on opposite cheeks on each fruit in the replicate using the UC firmness tester with a $12 \mathrm{~mm}$ tip. For soluble solids, acidity and $\mathrm{pH}$ measurements, we used juice pressed from a composite sample of 30 fruit per replicate. Starch degradation using an iodine test developed by Mitchell, which stained starch blue on the tissue, was used on each of the 30 fruit per replicate. Starch pattern was scored from $0=$ full starch on the core and cortex areas (immature) to $6=$ low starch on the cortex and core (overmature).

During both seasons, fruit samples at commercial harvest time (days after full bloom) were collected directly from the treatment trees and taken to UC's F. Gordon Mitchell Postharvest Laboratory in Parlier for detailed quality evaluation.

\section{Higher percentage of red color}

In the 1993 season, plastic reflective materials did not affect internal fruit quality measured at harvest and after a 4-month cold storage period (data not shown). However, visual red color development (percentage of red color) was significantly higher on fruit where reflective materials were used (table 1 ). The percent of red color was approximately $40 \%$ and $60 \%$ higher than the control where 20- and 40-inch reflective materials were used, respectively. Fruit from trees treated with the 40 inch reflective material had a higher percentage of red color than did fruit from trees treated with the 20 -inch reflective material. There were no differences in red color development between plastic and foil reflective materials when compared at the same width, although fruit from the 40 -inch foil reflective material had the highest red color intensity $\left(\mathrm{a}^{*}\right.$ and hue $\left.{ }^{\circ}\right)$. During this trial, we observed that more fruit were harvested at the first picking from the reflective material treatments than from the untreated.

During the 1994 season, flesh firmness, soluble solids, starch pattern degradation, acidity and $\mathrm{pH}$ were not affected by the reflective material treatments in either the Lincoln trellis or the central leader training system (tables 2 and 3). Since the two orchards were not adjacent nor the same age, we were not able to compare fruit quality between training systems.

With both training systems, the percentages of red color and red color intensity were significantly higher on fruit where reflective materials were used (tables 2 and 3). Fruit from trees where the 48-inch foil material was used had a higher percent red color and red color intensity than fruit where the 60 -inch plastic material was used. Percent of red color increased from 7.4 to 19.3 in the orchard with low red-color potential (Lincoln trellis) where the foil reflective material was used. In the orchard with high redcolor potential (central leader), percent red color was enhanced from 23.4 to 36.1 by using the foil reflective material.

Under "poor red-color orchard conditions," percent of red color and red color intensity were higher on fruit from the foil material treatment than on fruit from the plastic material treatment. Fruit from the plastic treatment had a higher percent red color and intensity than did fruit from the control. The central leader orchard had a low crop load with well-exposed fruit due to summer pruning. Under these "good red-color orchard conditions," 
the foil treatment enhanced the percent red color and intensity better than did plastic treatment in comparison to untreated (table 3 ).

Under both red-color development conditions, the reflective material treatments shifted the background color from green to yellow. Both materials were equally effective in enhancing this change under these different conditions.

\section{Earlier harvest, higher quality}

The benefits of the reflective materials were also confirmed on commercially packed fruit. The reflective materials induced an earlier harvest, larger sizes and higher quality fruit. Approximately $35 \%$ more fruit was picked and packed on the first harvest where the reflective materials were used compared to the control. Despite the earlier harvest, fruit size was not reduced (data not shown). Fruit from the reflective material treatments packed out larger sizes than did fruit from the untreated trees. More fruit in the Fancy and US \#1 fruit categories were packed from the reflective material treatments than from the control (table 4). The foil reflective material performed better than did the plastic reflective material under well-controlled conditions and commercial evaluations.

The plastic materials cost between $\$ 160$ and $\$ 200$ per acre and last just one season. The foil material used in this study costs approximately $\$ 900$ to $\$ 1,000$ per acre with a 3 -year reuse guarantee. Based on the 1994 apple prices supplied by the California Department of Food and Agriculture, Market News Branch, for category and size, the fruit value from the foil and plastic treatments justifies the use of the reflective material treatment.

H. Andris is Farm Advisor, UC Cooperative Extension, Fresno County and C.H. Crisosto is Postharvest Physiologist, Pomology Department, UC Davis, stationed at the Kearney Agricultural Center. The authors wish to express their thanks to Tad Kozuki and Gary Kozuki for their help with this study.

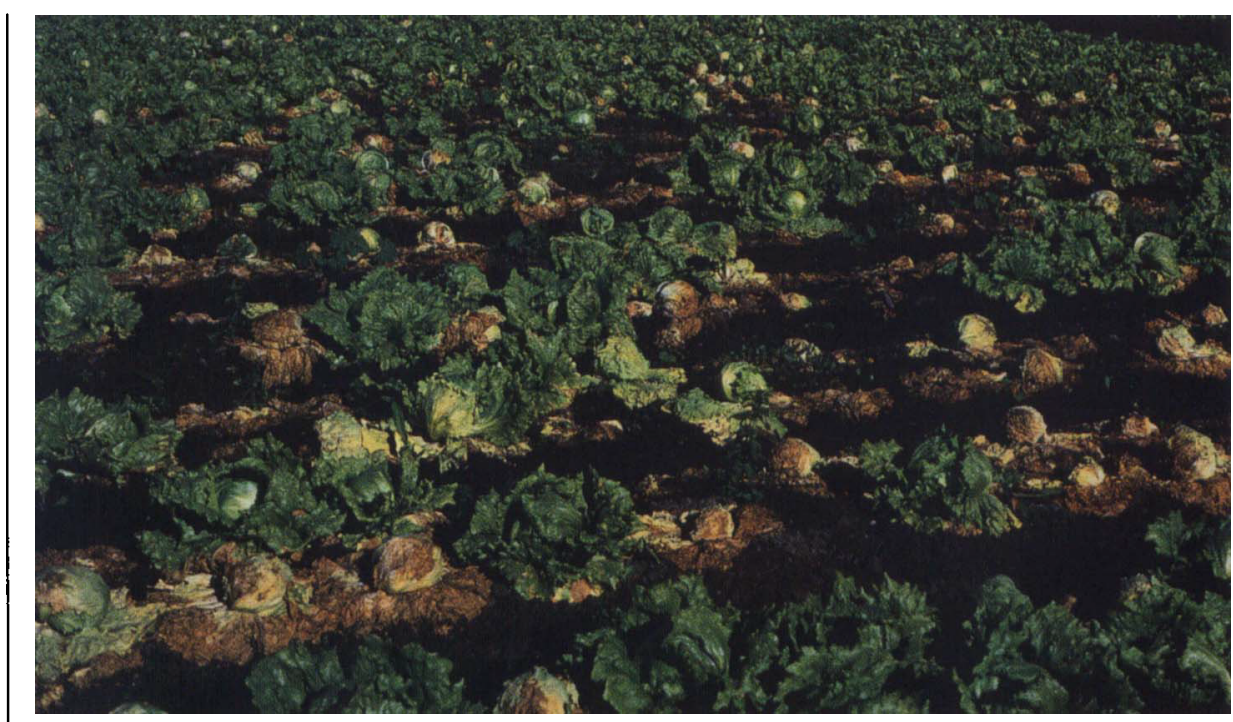

This field is infected by Sclerotinia minor, which causes lettuce drop. The disease causes a soft watery rot of both head and leaf lettuce that results in plant collapse and death.

\section{Deep plowing exacerbates lettuce drop in Salinas Valley}

Krishna V. Subbarao a Steven T. Koike a Judith C. Hubbard

Deep plowing is unlikely to be a successful disease management strategy for lettuce drop in the high-inoculum-density fields of the Salinas Valley. Research shows that the deep-plowing procedure may change the distribution of soilborne sclerotia, ultimately resulting in higher disease incidence.

Lettuce drop is an important disease throughout the lettuce-growing areas of California. The disease causes a soft watery rot of both head and leaf lettuce that results in plant collapse and death. Lettuce drop is caused by two species of Sclerotinia: S. sclerotiorum and S. minor. The two species are generally differentiated on the basis of sclerotia size, and they require different conditions for infection and differ in their mode of infection. In the coastal valleys of California, lettuce drop is predominantly caused by $S$. minor.

S. minor survives in soil as sclerotia that seldom produce the spore- producing structures called apothecia. All infections are caused by direct germination of sclerotia, and thus S. minor is strictly a soilborne pathogen. Large numbers of sclerotia are produced in colonized tissues of lettuce, and disease incidence is correlated with the number of these sclerotia in the soil. The majority of lettuce drop infections are caused by sclerotia located in the top 3.5 inches of soil and within about 0.75 inches of plant crowns.

Survival of $S$. minor sclerotia in soil is affected primarily by soil water and burial depth. Sclerotia either disintegrate or fail to germinate in very wet soils. They survive better in moderately moist soils, but their germination decreases progressively with time and depth of burial. Also, if sclerotia are moved from the top 4 inches of soil to depths greater than 4 inches, they are unable to cause lettuce drop infections.

With these principles in mind, deep plowing was developed as a diseasemanagement strategy, the object being to bury sclerotia at depths of 10 to 12 inches from the surface in order to reduce the number of sclerotia in the top 